\title{
Content Analysis of Tourist Opinion based on Tourism Quality (TOURQUAL) by Text Mining Online Reviews
}

\author{
The Case of Borobudur
}

\author{
Risca Septi Widyawati ${ }^{1}$, Herry Irawan ${ }^{2}$, and Astri Ghina ${ }^{3}$ \\ septirisca@student.telkomuniversity.ac.id ${ }^{1}$,herry.ir@telkomuniversity.ac.id ${ }^{2}$, \\ astrighina@telkomuniversity.ac.id ${ }^{3}$ \\ School of Economics and Business, Telkom University, Bandung, Indonesia
}

\begin{abstract}
The development of technology creates new phenomena that affect tourist behavior after visiting tourism destinations, one of the examples is exchange travel information and opinion of satisfaction or dissatisfaction with travel experiences through online review sites. The purpose of this research is to gain a deeper understanding of perceived destination-based tourism quality (TOURQUAL) using big data approach. This research applied selected text mining methods to investigates tourists' perceptions of Borobudur. Usergenerated content collected from TripAdvisor between 2016 and 2019 were processed. Through sentiment analysis, Borobudur has a good service quality with $83.4 \%$ positive and $16.6 \%$ negative sentiments. Then, all reviews were grouped into six TOURQUAL attributes using multiclass classification. The top 3 positive attributes are access, experience, and technical quality. Through a text network analysis, we found the summary of tourists' perceptions in the form of a network of the most frequent words used in social conversation. This research derives insights that useful to help businesses, especially the tourism industry to understand their visitors in a better way to improve their service quality performance.
\end{abstract}

Keywords: Borobudur, User Generated Content, Tourism Quality, Text Mining

\section{Introduction}

Tourism is an essential sector in the economy that has the fastest growth rate in the world. This sector defined as a leading sector in Indonesia plays a role by giving a significant contribution to the national economy. The tourism industry is projected as the main sector in bringing in foreign tourists to increase the country's foreign exchange and attract foreign investors to invest in Indonesia through the supporting tourism supply chain. Therefore, the Indonesian government decided to accelerate the development of tourist destinations in 5 
super-priority tourism destinations. One of the super-priority tourism destinations is the Borobudur temple, which is a historical heritage site designed as a world heritage by UNESCO, which is also one of the wonders of the world. Tourism service quality of tourism has become critical for a super-priority tourism destination to be sustainable and make a significant contribution to the national target. An assessment of the quality of tourism destinations can help tourism stakeholders in having a better comprehension of tourists ${ }^{6}$ perceptions and focusing their efforts to enhance tourists ${ }^{6}$ good experiences at tourism destinations. The level of positive attitudes accomplished by tourists may influence their future intentions to revisiting a destination and or giving recommendations to their friends. The service quality offered by destination management organization becomes an important thing to attract visitors, so it is important to assess the quality of destination from the tourists whether a service has a decent quality or not. Hence, the service quality of tourism destinations from tourists' perception is of prime importance.

Along with this, tourists 'perception can be known through the digital footprint of tourists that exist in online media. The development of the use of the internet has changed the way people behave in meeting their tourism needs, one of which is the search for information about tourist destinations to be visited, accommodation, itineraries references for tourist visits [1]. Therefore, the internet has become a major source of information about travel products and tourism destinations. Many tourists are active on social networking, blogs, and other online media platforms to share their opinion regarding their experiences when visiting some places. TripAdvisor is becoming popular and also the most influential site to inform travel choices and tourist behavior [2]. Therefore, usergenerated content found its way into the world of tourism and having an impact on the entire tourism industry [3]. The availability of user-generated content accessible from online website review TripAdvisor can be used to understand tourists ${ }^{6}$ perceptions toward their tourism experiences. The purpose of this research is to gain a deeper understanding of perceived destination-based service quality in Borobudur using big data approach. By implementing selected text mining methods, including sentiment analysis, multiclass classification, and text network analysis to investigates tourists' perceptions of Borobudur. This research derives insights that useful to help businesses, especially the tourism industry to understand their visitors in a better way to improve their service quality performance in a tourism destination. 


\section{Literature Review}

The empirical concept SERVQUAL [4] often used in evaluating the quality of service. But along with its development, the application of SERVQUAL has limitations. There is the concept of SERVPERF [5] which is used to overcome the limitations of the previous concept. However, SERVQUAL and SERVPERF are not enough to map the dynamics of service quality in the tourism sector so there is a concept of evaluating service quality in the tourism sector specifically such as DINESERV [6] for restaurant, HOTELQUAL [7] for hotel, HISTOQUAL [8] for historical site and museum, and also ECOSERV [9] for ecotourism. Mondo (2014) developed a concept to evaluate service quality specifically at a tourist destination, TOURQUAL which consists of 6 dimensions, namely accessibility, environment, human elements, safety, experience, and technical quality [10]. This concept has been used in several studies, such as those conducted by Khawash and Baksi (2017) using the TOURQUAL concept to assess the impact of perceived destination based on service quality on tourist satisfaction and destination loyalty [11]. Also, some studies use the TOURQUAL concept to measure behavioral intentions to revisit Pandawa Beach, Bali [12], and measure tourist satisfaction with a mystical cave in Antipolo, Rizal [13]. At the same time, this research is focusing on content analysis to evaluate the tourism destination quality based on TOURQUAL.

User-generated content is content that is posted by individuals via the internet and influences how people consume a service. User-generated content can be either positive or negative statements about a product and service made by consumers that are available to many people [14]. User-generated content is also known as electronic Word of Mouth (e - WOM). User-generated content is believed to be credible information because it can provide opinions correctly based on consumer experience so that it has no interest and does not favor certain parties [15].

User-generated content from tourists reviews toward their experiences on online media such as social networking and online website review TripAdvisor can be utilized to evaluate the quality of services. Several studies have been carried out by utilizing user-generated content from TripAdvisor, such as identifying tourist perceptions about tourism services in Macau [16] and tourism services in Paris [17]. Also, user-generated content can be used to determine consumer perceptions about the quality of airline services [18], hotel services in New York City [19], and the quality of Airbnb services in Sydney [20]. 


\section{Methodology}

Several stages were conducted throughout the process of this research. The research workflow is shown in this figure.

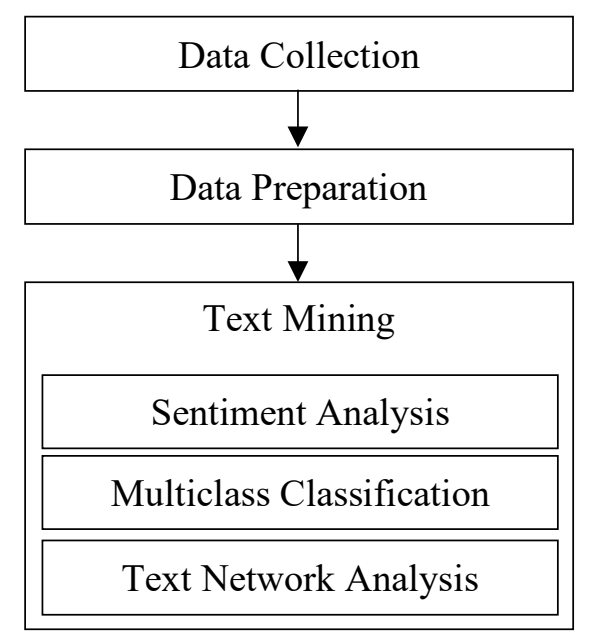

Fig. 1. Research Workflow.

\section{Data collection}

Data collection was performed based on the concept of user-generated content, where the data was derived from a website that contains an online review created by users. Tourists review regarding Borobudur temple that posted in the TripAdvisor review column is used. The reviews contain comments regarding their visit to tourism destination attraction. The data was obtained using a web-scraping technique to collect the data consist of an account of the reviewer and their reviews. Online reviews regarding Borobudur from 2016 to 2019 writing in English on online website review TripAdvisor are collected.

\section{Data preparation}

The data preparation stage is carried out by several techniques to obtain the final dataset, namely, data cleaning and data preprocessing. Data cleansing is a stage for remove noise or irrelevant data for the research objectives. Once the data is ready, then prepared into training data and testing data. Training data contains review data that has been labeled or grouped by previous categories to be studied by machine learning. While the testing data contains review data that is not labeled to test machine learning based on training data. The training data and testing data are used as input to machine learning, then proceed with the data preprocessing stage. 
The techniques performed at the data preprocessing stage include cleaning the data and restructuring the data so that the data can be analyzed in the next text mining process. The process of data preprocessing is carried out by three stages, namely tokenization, stopwords, and stemming that shown in Figure 2. The tokenization process is to divide a text into small and meaningful elements. While stopwords are words that often appear in text documents and have low value or meaningless. Stemming is the process of normalizing text into a standard language, the words in the text document will be transformed according to the grammatical context [21].

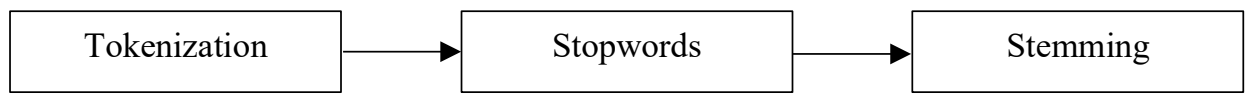

Fig. 2. Data Preprocessing Stage.

\section{Text Mining}

This research applied selected text mining methods, including sentiment analysis, multiclass classification, and text network analysis to investigates tourists' perceptions of Borobudur. Sentiment analysis is a process to derive opinion, sentiment, and subjectivity to determine whether positive or negative opinions towards the text document. In this research, we applied Naïve Bayes algorithm for sentiment analysis method. Naïve Bayes is a common method for text classification because the algorithm has strong independence and also a simple, efficient algorithm and does not require a large set of training data like other algorithms [22]. In this stage, sentiment analysis was conducted to distinguish tourists' positive and negative attitudes towards the categories recognized earlier. The positive sentiment represents the review with the tendency satisfied and feeling happy about their visit, while the negative sentiment represents the review with the tendency to unsatisfied feeling about their visit to destinations.

Sentiment analysis models that have been carried out need to be evaluated using several measurements. Figure 3 shows the confusion matrix that can be used to evaluate or measure the accuracy of the classification model by sentiment.

\begin{tabular}{|c|c|c|c|}
\hline & & \multirow{2}{*}{\multicolumn{2}{|c|}{ Predicted Label }} \\
\hline & & & \\
\hline & & Positive & Negative \\
\hline \multirow{2}{*}{$\begin{array}{l}\text { Actual } \\
\text { Label }\end{array}$} & Positive & True Positive (TP) & False Negative (FN) \\
\hline & Negative & False Positive (FP) & True Negative (TN) \\
\hline
\end{tabular}


True Positive (TP) Fig. 3. Confusion Matrix

: Appropriate classification result, predictable class classification is predicted positively by positive machine learning.

True Negative (TN) : Appropriate classification result, predictable class classification is predicted negatively by negative machine learning.

False Positive (FP) : Inappropriate classification result, predictable class classification is predicted negatively by positive machine learning.

False Negative (FN) : Inappropriate classification result, predictable class classification is predicted positively by negative machine learning.

Based on the values of True Positive (TP), True Negative (TN), False Positive (FP), and False Negative (FN), the results of machine learning performance evaluation in sentiment analysis can be seen from accuracy, precision, and recall.

$$
\begin{gathered}
\text { Accuracy }=\frac{\mathrm{TP}+\mathrm{TN}}{\mathrm{TP}+\mathrm{FP}+\mathrm{TN}+\mathrm{FN}} \\
\text { Precision }=\frac{\mathrm{TP}}{\mathrm{TP}+\mathrm{FP}} \\
\text { Recall }=\frac{\mathrm{TP}}{\mathrm{TP}+\mathrm{FN}}
\end{gathered}
$$

Accuracy is the level of correct prediction between predictive values and actual values. Besides accuracy, precision and recall are two measurements that are widely used to measure the performance of the classifier. Precision is a measurement ratio of how precise the classifier is in predicting text data. Recall is a measurement of how precise the classifier is in remembering text grouping data [23].

Multiclass classification provides a set of categories and collection of text documents so that the process is to specify an appropriate category for each document. Many studies have investigated the attributes and variables related to tourism destinations. In this research, we are interested in tourists' perceptions of Borobudur toward each identified category as its understanding can be used to observe customers' experience toward access, environment, experience, 
human element, security, or technical quality of destinations to improve customer experiences.

Instead of categorizing reviews, this research used a network perspective to capture the relationships among words within the review. We can identify the unique terms and their frequencies of occurrence. This method determines the structure of the whole set of words. The first step in this stage is capturing relationships among words and assigning word - pair link strength. The outcome of this step is used as the basis for text network structure mapping for more in-depth analysis. The next step is visualized the data into machine learning, once we import the data then the machine will create the whole text network consist of nodes and edges automatically, uncovering the structure of the relationship and insightful connection about the keywords. Therefore, we can identify what are the most discussed word in a text network for each category in each destination. Text network analysis is carried out annually to find out the dynamics of the text network from 2016 to 2019.

Table 1. Example of Text Classification by Sentiment

\begin{tabular}{ll}
\hline Review & Sentiment \\
\hline We went to Borobudur temple in the morning to see the sunrise. We & Positive \\
went during off season which was very nice because it wasn't very & \\
crowded. The temple is incredible, so grand and we felt very calm & \\
walking around the many levels of the temple with the surrounding & \\
forests and mountains. & \\
Nothing much to view. Just a large garden with not much Negative \\
landscaping and an UNESCO Temple building. Not worth the price \\
of the ticket. Don't waste your money here.
\end{tabular}

Table 2. Example of Text Classification by TOURQUAL Dimension

\begin{tabular}{|c|c|}
\hline Review & Dimension \\
\hline $\begin{array}{l}\text { The scenery from top of Borobudur was really awesome and } \\
\text { beautiful with mountain and forest hill view. }\end{array}$ & Environment \\
\hline $\begin{array}{l}\text { Ticket prices were a bit steep to enter but the place was well } \\
\text { maintained and worth the cost. }\end{array}$ & Technical Quality \\
\hline $\begin{array}{l}\text { If you hired a local guide, it could be a complete waste of your } 10 \\
\text { bucks. Basically, the guide might just give you some extra non info } \\
\text { and bring you to some non-photo spots. As you can tell, I was sorely } \\
\text { disappointed with my local guide. }\end{array}$ & Human Element \\
\hline $\begin{array}{l}\text { While the temple is a nice attraction, if not extremely overpriced, } \\
\text { seeing the 'elephant park' ruined the entire experience. Three } \\
\text { distressed elephants were chained up in a tiny barn while one was } \\
\text { chained in a more open, yet still small, area so tourists could feed it. }\end{array}$ & Experience \\
\hline $\begin{array}{l}\text { The site is handicapped unfriendly with its steep, uneven, stone steps, } \\
\text { no handrails. }\end{array}$ & Safety \\
\hline
\end{tabular}




\section{Result}

The results of Naive Bayes algorithm on machine learning in sentiment analysis have a good performance evaluation. Accuracy values describe how accurate machine learning can classify data correctly. The value of accuracy is $87.38 \%$ which predicated a good classification [24], while precision value reaches $76.81 \%$ and recall $77.50 \%$ as harmonization of precision and recall value showing the sentiment analysis process is working out in a good way. According to these values, it can conclude that process of sentiment analysis is considered a good classification. Based on the sentiment analysis result, during 4 years Borobudur has $83 \%$ positive and $17 \%$ negative tourists' perception toward its tourism quality. This percentage shows that positive sentiment dominates the overall review data, so it can be concluded that most tourists tend to have a good perception of service quality at Borobudur. Accordingly, it shows that Borobudur has good service quality performance that makes tourists feel satisfied with their experiences. However, to improve the overall quality of tourism service at Borobudur, it is necessary to have an understanding of what causes negative perceptions by tourists. From a set of negative perceptions, we can identify what makes tourists feel negative about Borobudur. We can build problem-solving priorities that could help tourism stakeholders to decide what issues should be managed first.

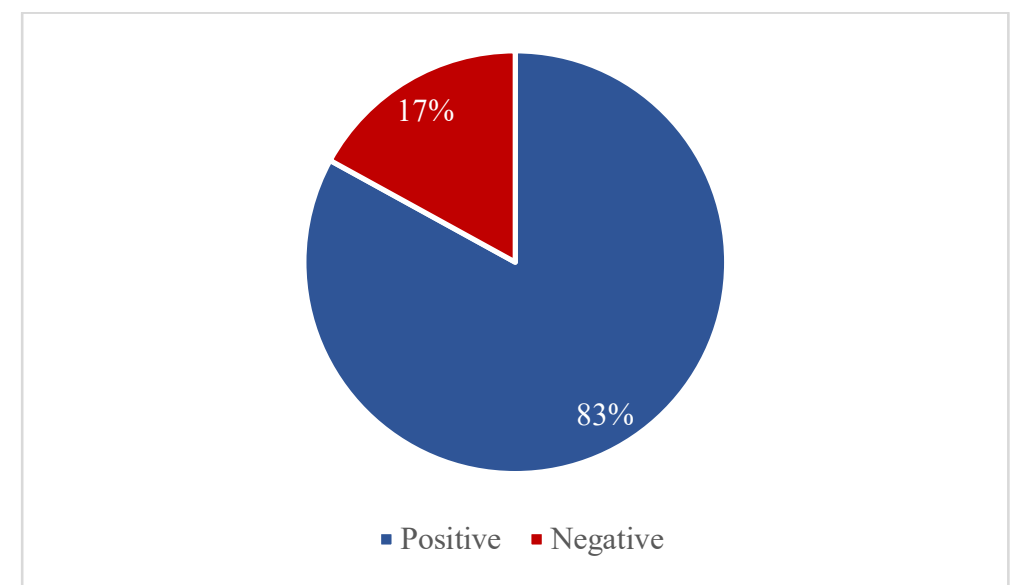

Fig. 4. Sentiment Analysis Result. 
To have a better understanding of tourists' perceptions of Borobudur, multiclass classification is applied to map tourists " perceptions about the service quality at Borobudur using TOURQUAL dimensions. In Fig. 2, we can see the classification of TOURQUAL dimensions of Borobudur. Environment is the most often discussed compared to other dimensions with $44 \%$ and experience comes second with $26 \%$. As for the other dimensions, tourists ${ }^{6}$ perceptions of Borobudur have been classified into technical quality of $17 \%$, human element of $8 \%$, access of $3 \%$, and $2 \%$ for security. Furthermore, this research used sentiment analysis and multiclass classification to identify the performance of each dimension. The largest negative tourists' perceptions are assigned to be the highest prioritized problems to solve by tourism stakeholders.

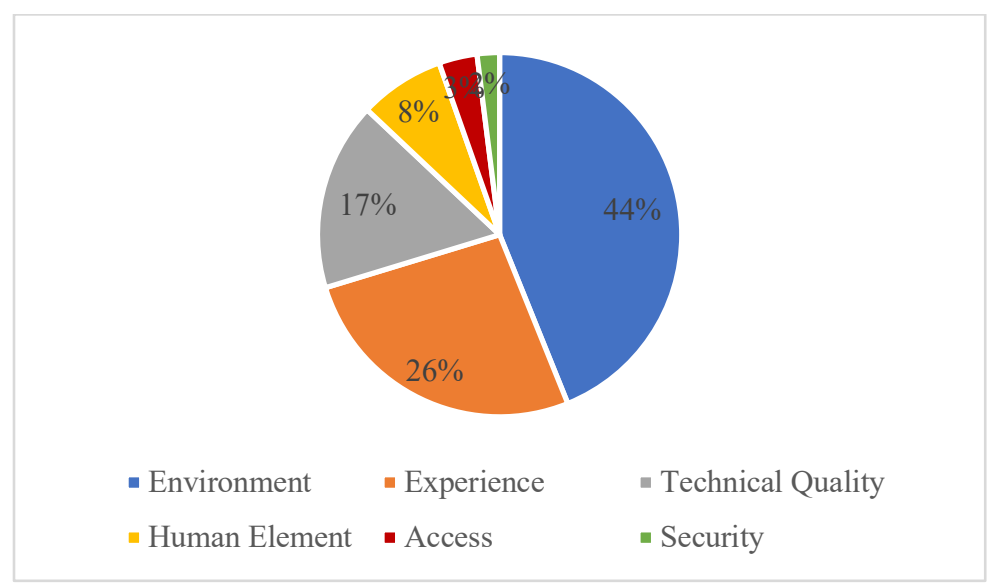

Fig. 5. Classification of TOURQUAL's Dimension

According to Table 3, Borobudur has a good tourism quality of TOURQUAL dimensions. From 2016 to 2019, tourists' perception related to environment has the highest positive proportion indicating that Borobudur's general environment dimension has the best performance than the other dimensions and could play a role in shaping positive tourists' perception. As well as human element and access dimensions are doing well. Besides that, problem-solving priorities are applied to identify what dimension must be improved first in order. Problem-solving priorities are arranged based on the highest amount of negative proportion in each dimension. The top 3 negative dimensions are technical quality, security, and experience. To have a better understanding of what makes these dimensions has a higher proportion of negative sentiment than other dimensions, we apply text network analysis to reveal why tourists feel negative about these dimensions in the form of text network. 
Table 3. Borobudur Dimension Proportion

\begin{tabular}{lll}
\hline \multirow{2}{*}{ Dimension } & \multicolumn{2}{l}{ Sentiment } \\
\cline { 2 - 3 } Environment & Positive & Negative \\
Experience & $93.5 \%$ & $6.5 \%$ \\
Human Element & $79.9 \%$ & $20.1 \%$ \\
Security & $91.4 \%$ & $8.6 \%$ \\
Technical Quality & $63.7 \%$ & $36.3 \%$ \\
Access & $62.7 \%$ & $37.3 \%$ \\
\hline
\end{tabular}

The result of the text network analysis formed by tourists' perception about Borobudur is carried out dynamically from 2016 to 2019 is presented in Fig. 3. The text network is constructed from nodes that represent the occurrence of words and edges that describe the relationship among those words. In Fig. 3, different nodes and edged colors mean different words cluster. There are 6 clusters in the text network, which represent 6 dimensions of TOURQUAL. Each cluster consists of several nodes that represent the characteristics of each dimension. Nodes on the text network also have different sizes, which indicate the intensity of the appearance of words from tourists' perception. The greater size of the nodes indicates the most mentioned words from tourists' perception which has been collected from TripAdvisor review. While the ticker edges mean more weight relations between nodes. From the text network, it is possible to identify and provide the tourists' needs toward specific services. Each color of nodes represents related issues of each TOURQUAL dimensions. The text network formed from tourists' perceptions about Borobudur commonly does not have differences of occurrences words from 2016 to 2019. The frequency of dominant words in each dimension from 2016 to 2019 partially have increased and decreased in intensity. Furthermore, the occurrence of edges in a text network makes it easy to interpret one word with another to get a good understanding of the dominant perceptions of tourists and get a summary of the topics discussed by tourists in their reviews.

\section{Environment}

The cluster of concepts associated with environment describes the surrounding of the temple, such as scenery, building, design, temple decoration. The occurrence of words that represent scenery such as 'valley', 'nature', 'mountain' is also connected to other words such as 'weather', 'atmosphere'. From 2017 until 2019 there is an occurrence of words 'sunrise' and 'sunset' represent that Borobudur temple has an amazing sunrise and sunset view, which is a good attraction for tourists. Borobudur has special operating hours with different rates for tourists who will enjoy the sunrise and sunset view. While 
occurrences of words 'sculpture', 'relief', 'wall', 'statue', and 'stupa' are representing another attraction is the gigantic temple itself with carvings on the walls that tell about the history and exciting Buddhist life, and also Buddha statues placed inside the stupa at each level of the temple. Most tourists have positive attitudes toward Borobudur's environment. Even though some tourists feel negatively associated with bad weather such as rain and sweltering weather, but they generally treated this as minor issues as long as they still enjoy the site.

\section{Experience}

Nodes that are associated with experience dimensions describe experiences at the tourism destination such as entertainment and learning process. Tourists' perceptions about experiences at Borobudur include historical and story, museum, animal ride, hotel and restaurants, and also shopping experiences. Experience related to the history of Borobudur and Buddhist life is highlighted by tourists that shown by high intensity of nodes 'historical', 'culture', and 'story' in text network over the 4 years. Besides that, Manohara Hotel is the most mentioned hotel by tourists when they stay in Borobudur. Words 'hotel' and 'manohara' are also connected to other words such as 'breakfast' and 'ticket' represent that Manohara Hotel provides an entrance ticket for Borobudur equipped with breakfast services and souvenirs. The only thing that could be seen as unfavorable is overcrowded tourists in peak season such as weekends or schools' holidays. The crowdedness of tourists visiting affects convenience while enjoying Borobudur. The other downside is the souvenir market at the exit of Borobudur is very long and quite tiring for tourists.

\section{Human Element}

The main concept in human element is interactions between tourists and staff or other human factors as customer service at tourism destinations. This dimension represents by occurrences of words 'staff', 'guide', 'english', and 'knowledge' that describe both staff and tour guides have excellent capabilities in delivering services including the ability to communicate in English and mastering knowledge of information related to the temple site. Tourists' perception mostly mentioned tour guides have a good performance in delivering Borobudur's storyline. Furthermore, local people are charming and friendly. The downside of human element dimension is related to aggressive hawkers that affect shopping experiences of tourists.

Security

Security dimension regarding Borobudur is mainly concerned with the stairs that connected levels at the site shown by occurrences of words 'stairs', 'high' and 'steep'. Tourists' perception over the years mostly describes the stairs in Borobudur are steep and slippery, so it is not easy to pass especially for children and the elderly. However, the occurrences of those words tend to have a reduced 
intensity from 2016 to 2019. This is because destination management makes improvements to give better security for tourists, such as adding handrails and attaching a rubber layer on stairs to protect the stone stair that is not worn and slippering due to being stepped on by tourists.

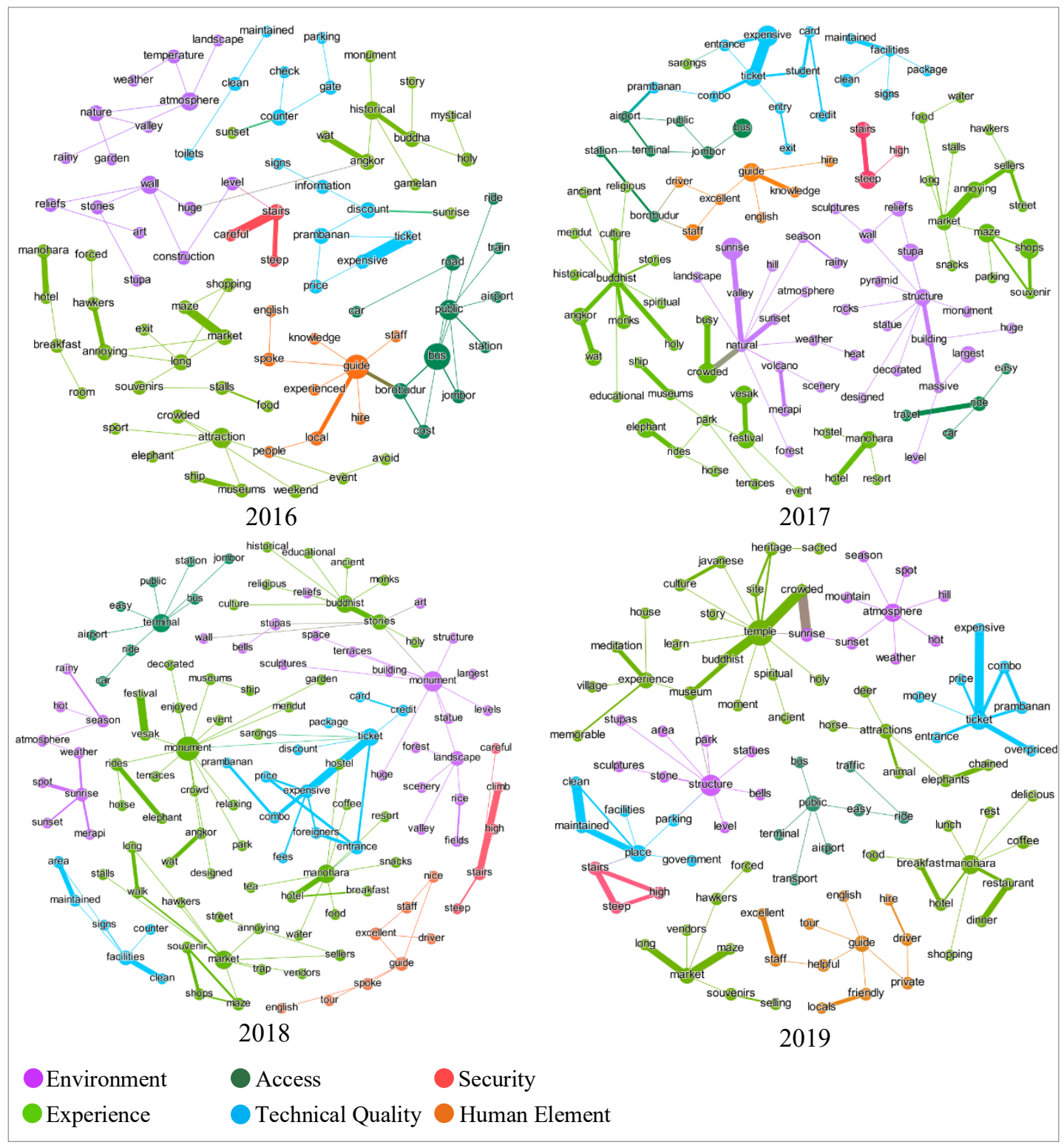

Fig. 6. Dynamic Text Network Analysis of Borobudur 


\section{Technical Quality}

Nodes associated with technical quality refer to the service delivery itself such as ticket price, infrastructure, internal signs, and cleanliness. The words cluster of technical quality dimensions represent that the temple is well managed, destination management carried out maintenance and cleaning the site routinely, and also taking care of the surrounding facilities such as toilets, entrance gates, parking area, and information boards. Borobudur is a world heritage site designated by UNESCO so that the temple complex is well preserved. However, the only downside is the high intensity of words 'ticket', 'expensive', 'discount', 'student', and 'prambanan' occurrences in text network from 2016 to 2019. This indicates that Borobudur entrance tickets are considered expensive by international tourists, which is significantly different from entrance tickets for local tourists. Nevertheless, entrance ticket discounts applied for bundling tickets for Prambanan Temple and also tourists who bring student cards will get a 50\% discount.

Access

Access dimension toward Borobudur mainly describes accessibility that allows the tourists to arrive at the site include public places such as terminal station and airport. Occurrences of words in text network from 2016 to 2019 regarding access dimension have no significant differences. In 2016, the word 'bus' has the highest intensity in text network represent that public bus can be used to get to the site location, by time passes there are various other modes of transportation available such as transportation by travel agents and online transportation which are indicated by the decreasing of the word 'bus' from 2017 to 2019. However, the road to Borobudur has a good condition so that tourists can drive using private transportation by car or motorcycle because of the easy access. Meanwhile, in 2019 there is the emergence of a new word in text network is 'traffic' that can be seen as a downside of access dimension, which indicates that there is a traffic jump that often occurs at peak seasons.

\section{Conclusion}

This research applied a text mining approach to perform a content analysis of the online website review TripAdvisor to provide a better understanding of tourists' perceptions and attitudes about Borobudur. Based on the methodological perspective, this research contributes to both the scientific community and the tourism industry. First, this research filled an important gap in the academic literature on tourists' perception in Borobudur based on online media platforms. The increasing of user-generated content, e.g., online website 
review has provided great opportunities and challenges of exploiting the large volumes of data to create business values. To date, little has been reported in the context of user-generated content from TripAdvisor that is associated with tourism industry. Other than that, this research applied service quality concepts of TOURQUAL to evaluate service quality at tourism destinations. This research also makes a contribution to recent research areas on big data and online media. By systematically producing visual representations of large amounts of data, it adds further insight into analytical methods in this area. Particularly, text network turns usual textual information into interesting visualization to help us deepen our understanding and quickly identify important information in tourists' perception of online website reviews.

Based on the perspective of the tourism industry, this research served to illustrate tourists' perception and mapped it into TOURQUAL dimensions to identify the quality of each dimension. This research help identify tourists' perception of important topics of concern regarding Borobudur as well as critical improvement areas. The result of this research discovers the driving factors of tourists' dissatisfaction with service quality at tourism destinations through customer-generated reviews on online sites. By using a well-authorized text mining method, factors getting to dissatisfaction that is hidden in unstructured textual data are disclosed. This research identified both positive and negative tourists' perceptions based on their travel experiences. So that tourism destination management could learn about and plan for dissatisfied tourists. Based on the sentiment analysis method, these research findings showed that Borobudur has a higher positive perception with $83 \%$ than a negative $17 \%$, indicates that Borobudur tends to has a good service quality. The finding of the multiclass classification process identified environment, experience, and technical quality as the most-mentioned topics on online website review TripAdvisor in general, respectively.

Furthermore, the finding showed that environment, human element, and access have a good performance. Slightly different, technical quality, security, and experience were the main dimensions tourists highlighted that needed improvement. Moreover, text network analysis is applied to extract the emerging keywords related to tourists' perception toward Borobudur over the years from 2016 to 2019. This method is applied not only to extract important keywords but also clusters of keywords. Clusters formed on the text network represent the TOURQUAL dimensions consist of environment, experience, human element, security, technical quality, and access. The above results showed that occurrences of words towards Borobudur have considerably not changed significantly over the last 4 years. However, the intensity of each word that represents each dimension sometimes varies over time, whether it is 
increasing or decreasing. The result of text network is used to reveal emerging words that can be seen as the downside of each TOURQUAL dimension. Text network visualization could provide detailed insights into the reasons why tourists feel negatively about specific services at tourism destinations. Such as, 'crowded' in Borobudur is one of the downsides that affects enjoyment in the travel experiences of tourists. With a solid understanding of issues perceived by tourists, tourism destination management can evolve an innovative and competent strategy focusing on a certain area that tourists pay attention to the most. Accordingly, tourism destination management can refine their emphasis and focus on their shortcomings in conveying service quality that requires earnest actions. Based on the findings in this research, tourism destination management should execute visitor management properly to handle and anticipate the increase of tourists at peak seasons to minimize overcrowded, improve infrastructure related to tourists' safety, consider the appropriateness of the price level with the quality of experience gained by tourists (value for money), and also rearrange the souvenir market and street vendor so that it can provide a more comfortable shopping experience for tourists.

The findings of this research have practical implications for the improvement of tourism destination's service quality. The potential information extracted from reviews on online website reviews is important for improving the service management and competitive advantage of tourism destinations. Using this approach, tourism destination management organizations can better and more accurately understand the tourists' perceptions and needs of tourists. Simultaneously, the finding in this research could prompt the development of new strategies for better services and improved tourists' experiences. Therefore, tourism destination management should focus on topics information that is perceived as negative to fix the issues.

Moreover, the result of this research can be utilized by tourism destination management organizations to offer an extent of service within tourists' desires and show that they care about their tourists. By understanding the voice of tourists, tourism destination management organizations can transform these online reviews into valuable knowledge that can benefit their service and business. To wrap things up, the newly discovered knowledge and insights from dissecting a tremendous measure of unstructured text data such as usergenerated content could be utilized by various stakeholders, such as tourism destination management organizations, hospitality service providers, tourism enterprises, government as policymakers, and educational institutes. 


\section{Limitation and Future Research Suggestion}

Although this research gives a step towards the use of textual data from online media, it is important to comprehend the limitations. The data reviews are gathered only from TripAdvisor.com as a representative online website review platform, thusly the findings of this research are restricted to one specific source. It would also be interesting to analyze different online website reviews such as Google Review and other websites, as well as to compare the results of various sites. This research can also be implemented in other destinations to gain a broader insight into tourism quality. Moreover, it is important to feature that this research only using reviews in English so the results may not reflect tourists' perceptions in other languages. This research can be extended in several ways in terms of the methodology used for analysis. For instance, although text classification using Naïve Bayes classifier is a viable and effective data-driven methodology, the data labeling phase still requires human involvement which poses subjectivity. Future research could address this limitation and make this human involvement of text classification more objective by two independent researchers. Lastly, this research also opens up for incorporating other data variables, such as ratings to enhance further insights related to service quality at tourism destinations.

\section{References}

[1] Cook, R. A., Hsu, C. H., \& Taylor, L. L. Tourism: the business of hospitality and travel. New York: Pearson; 2018. 70.

[2] Gursoy, D., Ouyang, Z., Nunkoo, R., \& Wei Wei. Residents' impact perceptions of and attitudes towards tourism development: a meta-analysis. Journal of Hospitality Marketing \& Management. 2019; 28(3): 306-333.

[3] Irawan, H., Widyawati, R. S., \& Alamsyah, A. Identification of tourism destination preferences based on geotag feature on Instagram using data analytics and topic modeling. Understanding Digital Industry. Proceedings of the Conference on Managing Digital Industry, Technology and Entrepreneurship (CoMDITE 2019); July 10-11, 2019. Bandung: Routledge. 2020. 280-283.

[4] Parasuraman, A., Zeithaml, V. A., \& Berry, L. L. Servqual: A Multiple-Item Scale For Measuring Consumer Perceptions of Service Quality. Journal of Retailing. 1988; 64.

[5] Cronin, J. J., \& Taylor, S. A. Measuring Service Quality: A Reexamination and Extension. Journal of Marketing. 1992; 55-68.

[6] Stevens, P., Knutson, B. and Patton, M. Dineserv: A tool for measuring service quality in restaurants. Cornell Hotel and Restaurant Administration Quarterly. 1995; 36: 56-60.

[7] Falces Delgado, C., Sierra Díez, B., Becerra Grande, A., \& Briñol Turnes, P. HOTELQUAL: a scale for measuring perceived quality in lodging services. Estudios Turísticos. 1999; 139: 95-110. 
[8] Frochot, I., \& Hughes, H. HISTOQUAL: The development of a historic houses assessment scale. Tourism management. 2000; 21(2): 157-167.

[9] Khan, M. ECOSERV: Eco tourists' quality perception. Annals of Tourism Research. 2003; 30(1): 109-124.

[10] Lohmann, G., \& Netto, A. P. Tourism Theory: Concepts, Models and Systems. London; CABI; 2017.

[11] Khawash, N., \& Baksi, A. K. Assessing the Impact of Perceived Destination-based Service Quality on Tourist Satisfaction and Destination Loyalty using TOURQUAL Protocol. Asian J. Management. 2017; 8(3): 688-694.

[12] Robustin, T. P., \& Hariyana, N. The effect of TOURQUAL dimensions on behavioral intentions to revisit Pandawa Beach, Bali, Indonesia. African Journal of Hospitality, Tourism and Leisure. 2019.

[13] Cruz, C. G., \& Dilao, A. M. Guest Satisfaction Plan for Mystical Cave: A Case in Antipolo, Rizal. Ioer International Multidisciplinary Research Journal. 2019; 1(2): 49-58.

[14] Moens, M. F., Li, J., \& Chua, T. S. Mining User Generated Content. New York: CRC Press, Taylor and Francis Group; 2014.

[15] Bahtar, A. Z., \& Muda, M. The Impact of User - Generated Content (UGC) on Product Reviews towards Online Purchasing - A Conceptual Framework. Procedia Economics and Finance. 2016; 337-342.

[16] Wong, C. U., \& Qi, S. Tracking the evolution of a destination's image by text-mining online reviews - the case of Macau. Tourism Management Perspective. 2017; 19-29.

[17] Kim, K., Park, O.-j., Yun, S., \& Yun, H. What makes tourists feel negatively about tourism destinations? Application of hybrid text mining methodology to smart destination management. Technological Forecasting and Social Change. 2017: 123; 362-369.

[18] Sezgen, E., Mason, K. J., \& Mayer, R. Voice of airline passenger: A text mining approach to understand customer satisfaction. Journal of Air Transport Management. 2019; 65-74.

[19] Hu, N., Zhang, T., Gao, B., \& Bose, I. What do hotel customers complain about? Text analysis using structural topic model. Tourism Management. 2019; 417-426.

[20] Cheng, M., \& Jin, X. What do Airbnb users care about? An analysis of online review comments. International Journal of Hospitality Management. 2019; 58-70.

[21] Hoffman, M., \& Chisholm. Text mining and visualization: case studies using open-source tools. CRC Press. 2016: 40.

[22] Maalej, W., \& Nabil, H. Bug report, feature request, or simply praise? on automatically classifying app reviews. 23rd international requirements engineering conference (RE). IEEE; 2015. 116-125.

[23] Williams, G. Data mining with Rattle and R: The Art of Excavating Data for Knowledge Discovery. Springer Science Business Media. 2011. 313.

[24] Gorunescu, F. Data Mining: Concepts, Models and Techniques. Berlin: Springer; 2011. 